\title{
DRUG-INDUCED LUPUS ERYTHEMATOSUS SECONDARY TO ANTI-TNF- $\alpha$ AGENTS IN PATIENTS WITH AXIAL SPONDYLOARTHRITIS AND PSORIATIC ARTHRITIS
}

\author{
Ana Martins ${ }^{1, \star}$, Daniela Oliveira ${ }^{1}$, Frederico Rajão Martins ${ }^{2}$, Filipe Oliveira Pinheiro ${ }^{1}$, Maria Seabra Rato ${ }^{1}$, Diogo Guimarães \\ Fonseca ${ }^{3}$, Salomé Garcia ${ }^{1}$, Bruno Miguel Fernandes ${ }^{1}$, Sofia Pimenta ${ }^{1}$, Miguel Bernardes ${ }^{1}$, Lúcia Costa ${ }^{1}$
}

1.Centro Hospitalar Universitário de São João, Porto (Douro Litoral), Portugal; 2.Centro Hospitalar Universitário do Algarve, Faro (Algarve), Portugal; 3.Centro Hospitalar de Vila Nova de Gaia/Espinho, Vila Nova de Gaia (Douro Litoral), Portugal.

*Corresponding author: anaigmartins.med@gmail.com

\section{BACKGROUND}

Induction of autoantibodies is frequently observed in patients treated with TNF- $\alpha$ antagonist and the possible development of drug-induced lupus erythematosus (DILE) remains a matter of concern. The prevalence of DILE secondary to anti-TNF- $\alpha$ therapy is $0.5-1 \%$. According to the literature, DILE due to anti-TNF- $\alpha$ agents differs in several ways from the clinical and laboratory findings typically associated with classic DILE.

\section{METHODS}

We performed a retrospective analysis of patients with spondyloarthritis (SpA) and psoriatic arthritis (PsA) treated with anti-TNFagents, from our university hospital, between July 2001 and December 2020. Patients with positive ANA (titer $>1 / 100$ ) before the anti-TNF- $\alpha$ therapy were excluded. Because specific criteria for the diagnosis of DILE have not been established, we considered the diagnosis in case of a temporal relationship between clinical manifestations and anti-TNF- $\alpha$ treatment and fulfillment of ACR/EULAR 2019 classification criteria for SLE. In patients with DILE, clinical features, laboratory findings, systemic therapies and outcome after anti-TNF-a discontinuation were collected from reuma.pt and medical records. For clinical and demographic predictors, continuous and categorical variables were analyzed using a two-sided t-test and Fisher's exact test, respectively. P-value $<0.05$ was considered statistically significant.

\section{RESULTS}

Two hundred and ninety patients were included in SpA group and 116 patients in PsA group. We observed high serology conversion rates (positive ANA in 67.9 and $58.6 \%$ of patients with SpA and PsA, respectively), with similar conversion rates between different anti-TNF drugs. Three patients with SpA (1.0\%) and one patient with PSA $(0.9 \%)$ developed DILE. Etanercept was the causative agent in two cases, infliximab and adalimumab in one case, each. Peripheral arthritis (new onset or abrupt worsening) occurred in two patients, serositis in one patient, constitutional symptoms in two patients, subnephrotic proteinuria in one patient, lymphopenia in two patients and hypocomplementemia in one patient. Specific treatment was prescribed to the four patients (oral corticosteroids) and they achieved complete recovery. After anti-TNF- $\alpha$ treatment interruption, no patient had recurrent disease. We observed that patients with DILE had a significantly longer disease duration $(p=0.04)$ and a significantly longer duration of anti-TNF therapy $(p=0.04)$ than patients without DILE.

\section{CONCLUSION}

Despite frequent induction of autoantibodies, the development of DILE secondary to anti-TNF- $\alpha$ agents is rare. Our study demonstrates an incidence rate similar to other studies reported before. The clinical and laboratorial characteristics of our patients with DILE due to anti-TNF- $\alpha$ agents differ from DILE due to more traditional agents, as is described in literature. Overall, patients in this study had mild disease that improved after therapy discontinuation, without recurrence of the disease. It seems that a longer disease duration and a longer period under anti-TNF- $\alpha$ therapy may increase the risk of DILE development.

\section{KEYWORDS}

Drug-induced lupus erythematosus, Anti-TNF- agents, Axial spondyloarthritis, Psoriatic arthritis. 